\title{
15 \\ Considering the Use of Standardized Clients in Professional Social Work Education
}

\author{
Irene Carter \& Judy Bornais \\ University of Windsor \\ Daniel Bilodeau \\ Conseil scolaire de district des écoles catholiques du Sud-Ouest
}

Counselling professionals seek to preserve their success by demonstrating excellent communication skills. Prior to contact with clients, students become familiar with counselling skills that reflect the needs of vulnerable populations. This involves creating a therapeutic relationship with the client using counselling skills. One way to promote student confidence in counselling education is to consider the use of standardized clients. The authors discuss the effectiveness of using standardized clients in teaching counselling skills in social work education. The discussion considers the benefits and challenges of using standardized clients in social work education as well as other professions and the need for scholarly research on the effectiveness of this teaching tool.

\section{Introduction}

Tnterviewing skills play an integral role within the field of social work (Petracchi \& Collins, 2006; Rogers \& Welch, 2009). They are often considered the most essential skills used within all levels of practice (Petracchi \& Collins, 2006). Furthermore, interviewing skills are seen as the catalysts by which micro, mezzo, and macro levels of practice are implemented (Petracchi \& Collins, 2006). In order to effectively communicate, helping professionals are encouraged to listen, empathize, and develop therapeutic rela- tionships with clients (Rogers \& Welch, 2009); thus, creating a need for educational initiatives which promote and refine the development of these skills.

Social work students must familiarize themselves with a variety of counselling skills prior to practicing within the community. In order to increase clinical skills amongst students, simulated exercises are often required (Lane, Slavin, \& Ziv, 2001). Current social work curriculums often foster communication and assessment skills through 
the use of standardized clients or peer facilitated role plays (Badger \& MacNeil, 2002; Petracchi \& Collins, 2006; Rogers \& Welch, 2009; Todd, 2011). Standardized clients are trained individuals who portray various characteristics within simulated counselling sessions (Badger \& MacNeil, 2002; Petracchi \& Collins, 2006; Todd, 2011). Badger and MacNeil (2002) define standardized clients as "nonprofessionals who are trained to take on the full spectrum of characteristics of an assigned client case" (p. 365). Furthermore, Todd (2011) reports that "standardized clients are traditionally lay persons who are trained to realistically simulate physical signs, emotions and affect, symptoms, and behaviors while working from a character sketch or script" (p. 2). The following sections will examine the evolution and effectiveness of standardized clients in social work, as well as other disciplines.

\section{Background on Social Work Education}

Social work practice has evolved from two key historical movements, which consisted of settlement houses and charitable organizations (Greene, 2005; Holosko, 2003; Stuart, 1999). In promoting and establishing social justice, the profession helped individuals, as well as society, through these pathways (Holosko, 2003). Social work focused on individuals experiencing substandard living conditions (Greene, 2005), targeting individual and social reforms to promote the wellbeing of those living in poverty (Holosko, 2003; Stuart, 1999). Settlement houses focused on immigration and macro level changes, while charitable organizations targeted individuals as well as families (Greene, 2005). Ultimately, the profession's goal was to help individuals' better themselves in an attempt to effectively function within society (Holosko, 2003).

Social work gathered most of its strength through its close relationship with the people it serves and by gaining a thorough understanding of the environmental factors affecting these individuals (Stuart, 1999). Instead of solely specializing in a specific area of practice, social work developed a generalist practice model that has remained consistent since its inception (Hall, 2008). In social work, a generalist is "a practitioner whose knowledge and skills encompass a broad spectrum and who assesses problems and their solutions comprehensively" (Barker, 2003, p. 176-177). Rather than specializing in any one area, generalist social workers possess knowledge and skills in a wide range of client needs which they can apply to social services delivery. Dimensions in the definition of generalist practice include theoretical and problem solving approaches, using ethical principles, social work values, as well as a wide range of roles and skills (Kirst-Ashman, \& Grafton, 2010).

Although the field of social work has maintained a generalist approach which utilizes a knowledge base formulated from a wide spectrum of disciplines (Greene, 2005), the profession has continued to evolve. For instance, Hall (2008) reports that social work's eclectic methodology allows practitioners to easily transition from one methodology to another. Furthermore, in the interest of increasing and enhancing professional credibility, social workers participated in evidenced-based practice, helping the profession identify proven tools and methods to establish desired outcomes (Hall, 2008). The use of standardized clients has been implemented and promoted as one such effective educational strategy; thus, establishing itself as one of the many educational tools utilized within the social work profession.

\section{Standardized Clients in Social Work}

The use of standardized clients provides a pathway to transfer theoretical and practical knowledge to simulated practice settings. Although the term often refers to an educational strategy used within social work curriculums, it is not solely restricted to the social work profession. Standardized patients have been used in medical education for over three decades (Wallace, Rao, \& Haslam, 2002). In addition, nursing education programs have used standardized patients to help teach interviewing and physical assessment skills (Konkle-Parker, Cramer, \& Hamill, 2002). Similar to standardized clients, standardized patients 
are "nonprofessionals who are trained to take on the full spectrum of characteristics of an assigned case" (Badger \& MacNeil, 1998, p. 207). As educational tools, standardized clients and standardized patients have played an integral role in transferring knowledge to practice.

Standardized clients are conceptually similar to standardized patients and aim to promote strong interviewing skills within educational settings (Rogers \& Welch, 2009). Miller (2004) identifies the use of standardized clients as a strategy which allows students to learn and enhance various practice skills in a safe and ideal learning environment. However, it has been well documented that establishing safe and realistic practice environments can be quite challenging (Rogers \& Welch, 2009). Furthermore, transferring course content to a practice setting has often been difficult to achieve. For instance, Rogers and Welch (2009) report that teaching abstract concepts and interviewing skills can be quite challenging in educational settings, especially with regards to creating a realistic practice environment as well as transferring learned material to actual practice settings.

Social work students must learn how to empathize, effectively listen and communicate, as well as develop a professional relationship with clients (Rogers \& Welch, 2009). Thus, standardized clients can provide a safe opportunity for students to practice and apply these skills within a simulated practice setting. Students need to be able to apply theoretical skills in university as well as agency settings (Crisp, Anderson, Orme, \& Lister, 2004). Using standardized clients creates a professional environment whereby students can practice interviewing skills, learn from their experiences, and receive feedback on how to enhance their skills (Rogers \& Welch, 2009). Mooradian (2008) identifies simulated client sessions as a means to enhancing the overall learning process within social work curriculums.

\section{Comparing role plays and standardized clients}

Traditionally, social work curriculums encouraged students to read course material, engage in classroom discussions, and transfer applicable skills while engaging in role plays with classmates (Rogers \&
Welch, 2009). As an educational strategy, role plays have also promoted critical thinking amongst its students (Ertmer et al., 2010). However, Rogers and Welch (2009) identify several concerns associated with the use of role plays in social work curriculums, such as, student feedback and role plays that are often not taken seriously, student inability to understand the meaning behind taught concepts and skills, as well as the lack of realism associated with a role play. As an evolved and more advanced form of role plays (Badger \& MacNeil, 1998, 2002), standardized clients have been introduced into social work curriculums in order to create a more effective and realistic learning experience.

Role plays are an inexpensive frequently used tool in social work curriculums which aim to enhance the interviewing skills of students. They are often completed in dyads or triads consisting of an interviewer, a client, and an observer (Moss, 2000; Petracchi \& Collins, 2006). Moss (2000) states that role plays can also consist of large groups of students; however these groups should not exceed 25 students in order to include everyone in the role play. Similar to standardized clients, instructors can often determine the level of complexity associated with a particular role play (Petracchi \& Collins, 2006). Unfortunately, Badger and MacNeil (1998) report that role plays lack both internal validity and authenticity. Ultimately, limited information exists on how to properly incorporate role plays within academic curriculums (Petracchi \& Collins, 2006).

Miller (2002) states that although both role plays and standardized clients offer great learning opportunities, the use of standardized clients provides a higher degree of realism. Furthermore, Miller (2002) identifies several advantages associated with utilizing standardized clients in both undergraduate and graduate level courses. First, standardized clients create a more realistic encounter in which trained actors accurately and consistently portray the characteristics and affect of a particular client and do not divulge pertinent details unless asked. Second, standardized clients often utilize a checklist to evaluate the student's performance and provide quality feedback. Third, the use of standardized clients can help enhance a student's clinical skills across a wide spectrum of settings. Lastly, 
this educational tool also presents students with various ethical dilemmas which they could possibly face in a real practice setting which they might otherwise not be exposed to in their educational experience as students.

When examining the implementation of standardized clients, Badger and MacNeil (2002) identify several educational advantages. Using standardized clients presents an opportunity to expose students to a wide spectrum of clients and issues which may not be encountered during field placements. Faculty can determine which characteristics standardized clients will portray. Standardized clients can be utilized as both a training and evaluation tool which allows students to think critically about themselves as well as the client. Lastly, Badger and MacNeil (2002) state that students and instructors perceive the use of standardized clients as an effective educational tool. Moreover, the authors report the cost of standardized clients as being relatively low for an educational tool that can enhance an individual's assessment and practice skills.

In examining the effectiveness and feasibility of standardized clients, Badger and MacNeil (2002) report that students who were exposed to standardized clients as an educational strategy did better than those who solely engaged in role plays. The study used a three year approach consisting of three separate Masters of Social Work cohorts. The first cohort were not exposed to standardized clients and served as the control group. The second and third cohorts were both exposed to standardized clients; however, the later also had access to videotaped interviews. Badger and MacNeil (2002) did not find significant improvements between the second and third cohorts; however, the authors indicate that standardized clients are an effective educational strategy.

\section{Costs in using standardized clients}

The cost of using standardized clients is often viewed as prohibitive as the cost is greater than role plays or standard instruction (Badger \& MacNeil, 1998; Petracchi \& Collins, 2006). In many circumstances social work programs may not have the means to pay for the use of standardized clients. Fortunately, Petracchi and Collins (2006) utilize a particular process which can help mitigate the costs of standardized clients. For instance, the authors recruit acting students to play the role of the standardized clients. This practical approach offers a relatively cost free way to utilizing this learning tool. In the end, Badger and MacNeil (2002) state that the costs of utilizing standardized clients averages anywhere from $\$ 25$ to $\$ 40$ an hour, an amount many consider minimal (Badger \& MacNeil, 1998; Miller, 2002, 2004).

\section{Standardized Clients and Patients in Other Disciplines}

As previously stated, standardized clients and standardized patients are currently being used within numerous academic disciplines. In fact, when compared to other academic disciplines, the research on the effectiveness of standardized clients within the field of social work is relatively limited. Standardized clients and patients have often been used in the following post secondary programs: law, medical, pharmaceutical, substance abuse counselling, and nursing (Austin, Gregory, \& Tabak, 2006; Fussel, Lewy, \& McFarland, 2009; Grosberg, 2001; Lourdes \& Nelson, 2008; McWilliam \& Botwinski, 2010; Stimmel, Cohen, Fallar, \& Smith, 2006; Vessey \& Huss, 2002). Thus, the information acquired by these disciplines can assist the social work profession in effectively implementing this educational strategy.

Shawler (2008) examines the use of standardized patients as a learning instrument for psychiatric nurse practitioner students. Coinciding with its use in social work, the learning strategy was being utilized as both an evaluation and training exercise. Shawler (2008) reports that the students were given content pertaining to a specific mental disorder prior to the interview. Then, the students conducted a 30-minute interview with a standardized patient, followed by a review. The initial review included feedback from the standardized patient for approximately 15 minutes based on a checklist the standardized patient had to complete. Next, the students reviewed their performance utilizing a videotaped copy of their interview with a faculty member. Upon completing the previous steps, 
Shawler (2008) mentions that the students completed a final interview with a standardized patient as well as a final paper for the course, which was followed by faculty evaluations. Ultimately, students who participated in this study reported feeling more prepared and confident with their refined skill set by displaying advanced interviewing and assessment skills, effectively utilizing screening and diagnostic tools, and accurately diagnosing standardized patients (Shawler, 2008).

Bennett, Arnold, and Welge (2006) also report promising results with the implementation of standard patients in a psychiatry clerkship. Fourthyear medical students who received a standardized patient examination during their third year psychiatry clerkship performed better than fourth-year students who did not receive this examination. Both groups of students were examined using a clinical competency examination. Bennett et al. (2006) suggest that the use of standardized patients throughout a psychiatry clerkship may enhance interviewing and interpersonal skills amongst medical students. The authors recommend that additional studies need to be completed in order to accurately identify the advantages associated with this learning strategy.

Despite the increased attention given to the use of standardized patients as an evaluative tool within the field of nursing, little research has evaluated its effectiveness. As seen in the social work literature, standardized patients in nursing can also adjust the complexity of their character depending on the assigned situation (Vessey \& Huss, 2002). Moreover, standardized patients also can provide nursing students with feedback based on their performance (McWilliam \& Botwinski, 2010; Vessey \& Huss, 2002). However, Vessey and Huss (2002) note a disadvantage to using standardized patients. They identify that nursing students can only be evaluated on a limited range of skills, as standardized patients can only portray a limited number of clinical conditions. They also note that standardized patients are considered expensive and that accurate evaluations utilizing this method can be quite difficult to achieve.

Pharmaceutical curriculums are also seeking to implement educational strategies which promote positive communication skills (Boesen, Herrier,
Apgar, \& Jackowski, 2009). In a unique design, Westberg, Adams, Thiede, Stratton, and Bumgardner (2006) introduce an interprofessional approach to using standardized patients. The study intends to enhance pharmaceutical students' collaboration with students from other health based disciplines as well as increase their communication skills. As a team, pharmacy, medical, and nursing students worked together to assess a standardized patient and formulate a comprehensive service plan. The authors conclude that the pharmacy students enhanced their understanding of how nurses, physicians, and pharmacists can collaborate in order to provide a more holistic approach to service delivery. This particular interprofessional learning strategy is very promising, however, Westberg et al. (2006) describe it as difficult to establish, coordinate, and maintain.

\section{Conclusion and Future Direction}

Standardized clients offer a viable and practical learning opportunity to prospective social workers attempting to refine and enhance their skill sets. Within educational settings, standardized clients provide students with a safe and secure environment towards attaining pathways which facilitate the transferring of classroom and theoretical knowledge to practice (Miller, 2004). Standardized clients present prospective helping professionals with an opportunity to acquire or enhance a technique prior to encountering actual practice situations (Miller, 2002, 2004).

Although current studies have reported positive trends pertaining to the overall effectiveness of both standardized clients and standardized patients as educational learning strategies (Badger \& MacNeil, 2002; Miller, 2002; Wallace, Rao, \& Haslam, 2002), limited information exists on their use and effectiveness within social work curriculums. Badger and MacNeil (2002) state that only a few articles conducted by social work researchers have examined the impact of standardized clients. Despite the need for additional research, standardized clients may serve a dual purpose within social work curriculums. For instance, they provide an opportunity for students 
to further refine their skill sets and allow faculty or standardized clients to evaluate a student's ability to properly utilize a learned skill or concept (Badger \& MacNeil, 2002). However, due to their costs (Crisp et al., 2004), significant advantages must be sought out in order to further implement them within social work curriculums. Indeed, further research is required to examine the use of standardized clients within social work curriculums. Additional research should also be directed towards enhancing this learning tool. Therefore, upcoming studies should identify guidelines and strategies directed towards proper utilization of standardized clients within classrooms.

\section{Acknowledgements}

This project was made possible by a grant from the Centred on Learning Innovation Fund, Centre for Learning and Teaching, University of Windsor.

\section{References}

Austin, Z., Gregory, P., \& Tabak. D. (2006). Instructional design and assignment: Simulated patients vs. standardized patients in objective structured clinical examinations. American Journal of Pharmaceutical Education, 70(5), 1-7.

Badger, L.W. \& MacNeil, G. (1998). Rationale for utilizing standardized clients in the training and evaluation of social work students. Journal of Teaching in Social Work, 16(1), 203-218.

Badger, L.W. \& MacNeil, G. (2002). Standardized clients in the classroom: A novel instructional technique for social work educators. Research on Social Work Practice, 12(3), 364-374.

Barker, R.L. (2003). The social work dictionary (5th ed.). Washington, DC: NASW Press.

Bennett, A.J., Arnold, L.M., \& Welge, J.A. (2006).
Use of standardized patients during a psychiatry clerkship. Academic Psychiatry, 30(3), 185-190.

Boesen, K.P., Herrier, R.N., Apgar, D.A., \& Jackowski, M. (2009). Innovations in teaching: Improvisational exercises to improve pharmacy students' professional communication skills. American Journal of Pharmaceutical Education, 73(2), 1-8.

Crisp, B.R., Anderson, M.R., Orme, J., \& Lister, P.G. (2004). Learning and teaching assessment: Reviewing the evidence. Social Work Education, 23(2), 199-215.

Ertmer, P.A., Strobel, J., Cheng, X., Chen, Z., Hannah, K., Olesova, L., Sadaf, A., \& Tomory, A. (2010). Expressions of critical thinking in role-playing simulations: comparisons across roles. Journal of Computing in Higher Education, 22(2), 73-94.

Fussel, H.E., Lewy, C.S., \& McFarland, B.H. (2009). Evaluating and training substance abuse counsellors: A pilot study assessing standardized patients as authentic clients. Substance Abuse, 30(1), 47-60.

Greene, R. (2005). Redefining social work for the new millennium. Journal of Human Behavior in the Social Environment, 11(1), 37-54.

Grosberg, L.M. (2001). Medical education again provides a model for law schools: The standardized patient becomes thestandardized client. Journal of Legal Education, 51(2), 212234.

Hall, R. (2008). The evolution of social work practice: Implications for the generalist approach. International Journal of Social Welfare, 17, 390-395.

Holosko, M. J. (2003). The history of the working definition of practice. Research on Social Work 
Practice, 13(3), 271-283.

Kirst-Ashman, K.K. \& Grafton, H.H. (2010). Understanding generalist practice $\left(6^{\text {th }}\right.$ ed.). Belmont, CA: Brooks/Cole.

Konkle-Parker, D.J., Cramer, C.K., \& Hamill, C. (2002). Standardized patient training: A modality for teaching interviewing skills. The Journal of Continuing Education in Nursing, 33(5), 225-230.

Lane, J.L., Slavin, S., \& Ziv, A. (2001). Simulation in medical education: A review. Simulation \& Gaming, 32(3), 297-314.

Lourdes, G.P. \& Nelson, L. (2008). Innovations in teaching: A systems approach to scaffold communication skills development. American Journal of Pharmaceutical Education, 72(2), $1-12$.

McWilliam, P. \& Botwinski, C. (2010). Developing a successful nursing objective structured clinical examination. Journal of Nursing Education, 49(1), 36-41.

Miller, M. (2002). Standardized clients: An innovative approach to practice learning. Social Work Education, 21(6), 663-670.

Miller, M. (2004). Implementing standardized client education in a combined BSW and MSW program. Journal of Social Work Education, 40(1), 87-102.

Mooradian, J. (2008). Using simulated sessions to enhance clinical social work education. Journal of Social Work Education, 44(3), 2135.

Moss, B. (2000). The use of large-group role play techniques in social work education. Social Work Education, 19(5), 471-483.

Petracchi, H.E. \& Collins, K.S. (2006). Utilizing actors to simulate clients in social work student role plays. Journal of Teaching in Social Work, 26(1), 223-233.

Rogers, A. \& Welch, B. (2009). Using standardized clients in the classroom: An evaluation of a training module to teach active listening skills to social work students. Journal of Teaching in Social Work, 29(2), 153-168.

Shawler, C. (2008). Standardized patients: A creative teaching strategy for psychiatric-mental health nurse practitioner students. Journal of Nursing Education, 47(11), 528-531.

Stimmel, B., Cohen, D., Fallar, R., \& Smith, L. (2006). The use of standardized patients to assess clinical competence: Does practice make perfect? Medical Education, 40, 444449.

Stuart, P.H. (1999). Linking clients and policy: Social work's distinctive contribution. Social Work, 44(4), 335-347.

Todd, S. (2011). Practicing in the uncertain: Reworking standardized clients as improv theatre. Social Work Education, 1-14, First published on 10 March 2011 (iFirst).

Vessey, J.A. \& Huss, K. (2002). Using standardized patients in advanced practice nursing education. Journal of Professional Nursing, 18(1), 29-35.

Wallace, J., Rao, R., \& Haslam, R. (2002). Simulated patients and objective structured clinical examinations: Review of their use in medical education. Advances in Psychiatric Treatment, 8,342-350.

Westberg, S.M., Adams, J., Thiede, K., Stratton, T.P., \& Bumgardner, M.A. (2006). Innovations in teaching: An interprofessional activity using standardized patients. American Journal of Pharmaceutical Education, 70(2), 1-5. 


\section{Biographies}

Irene Carter is an assistant professor, School of Social Work, University of Windsor. Developmental and intellectual disabilities, self-help groups, disability studies, and continuing professional education are Irene's main areas of interest.

Judy Bornais is an experiential learning specialist in the Faculty of Nursing, University of Windsor. Judy's research focuses on nursing pedagogy, including the use of standardized patients to improve students' health assessment skills, the use of peer mentors, the use of simulation technology to reinforce and foster caring in nursing students.

Daniel Bilodeau is a social worker employed with the Conseil scolaire de district des écoles catholiques du Sud-Ouest. Daniel has research interests in professional development, mental health, and selfcare. 